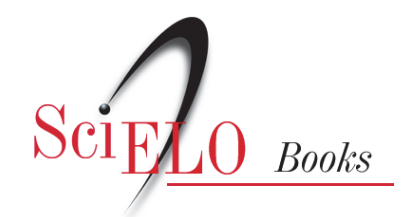

\title{
Feduepb
}

\section{Pensar alternativamente e agir solidariamente}

\author{
José Marques de Melo
}

\section{SciELO Books / SciELO Livros / SciELO Libros}

MELO, JM. Cidadania glocal, identidade nordestina: ética da comunicação na era da internet [online]. Campina Grande: EDUEPB; Latus, 2011. 108 p. ISBN 978-85-63984-07-4. Available from

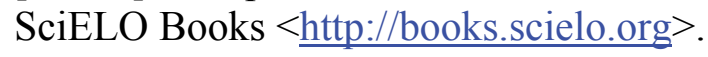

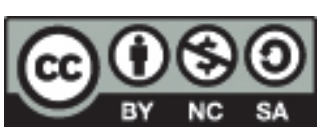

All the contents of this work, except where otherwise noted, is licensed under a Creative Commons Attribution-Non Commercial-ShareAlike 3.0 Unported.

Todo o conteúdo deste trabalho, exceto quando houver ressalva, é publicado sob a licença Creative Commons Atribuição Uso Não Comercial - Partilha nos Mesmos Termos 3.0 Não adaptada.

Todo el contenido de esta obra, excepto donde se indique lo contrario, está bajo licencia de la licencia Creative Commons Reconocimento-NoComercial-CompartirIgual 3.0 Unported. 


\section{Pensar alternativamente e agir solidariamente ${ }^{3}$}

O que torna diferente esta honraria, afetuosamente concedida pela Universidade Estadual da Paraíba, evocando a celebração dos meus 50 anos de jornalismo, se comparada as outras que venho recebendo, no país e no exterior?

Trata-se de detalhe que pode escapar à percepção geral, mas que me deixa particularmente orgulhoso, ao receber o título de Professor Honoris Causa.

3 Discurso proferido em Campina Grande (PB), na noite de 10 de junho de 2010, durante a outorga do título de Professor Honoris Causa pela Universidade Estadual da Paraíba. 
Refiro-me à circunstância desse reconhecimento ter a marca de uma comunidade interiorana, o selo de uma universidade comprometida com os anseios do povo rústico da minha região. Mais do que isso: trata-se de um testemunho dos meus colegas que se dedicam ao estudo da cultura popular, um campo de pesquisas e reflexões que tem sido desdenhado ou desqualificado pelo claustro acadêmico, melhor sintonizado com os interesses das elites dominantes.

Desde o nascimento do curso de comunicação de Campina Grande, fruto da teimosia de colegas que não desistem facilmente dos projetos de interesse coletivo, venho acompanhando sua vocação regional, seu compromisso popular, seu perfil comunitário, sua identificação com as demandas das classes subalternas.

E tenho estimulado, presencialmente ou a distância, a manutenção dessa linha de pesquisa, mesmo que enfrentasse a incompreensão dos detentores do poder universitário, aqui, em João Pessoa ou em Brasília. Não se trata apenas de remar contra a maré dos que se sentem partícipes incondicionais da arena global, mas de vencer a obtusidade dos que se deixam iludir pelas aparências de uma sociedade que se diz pós-moderna, descartando as identidades nacionais e jogando, na lata do 
lixo da História, as peculiaridades regionais e as especificidades locais ou até mesmo os singulares paroquialismos.

Enganaram-se redondamente os que acreditavam numa sociedade unidimensional, matizada pelas cores da metrópole unipolar, cuja indústria cultural tenta dominar mercados, ameaçando as diferenças enraizadas em tradições seculares. Paradoxalmente, o suporte principal dessa sociedade que se pretende mundializada vem favorecendo os povos e as comunidades que não se renderam ao mimetismo, que resistiram à padronização simbólica.

Esse cavalo de troia engendrado pela magia da eletrônica e refinado pelas malhas da carpintaria digital se chama internet. Nas suas entranhas, vem germinando uma nova realidade. Nela, desponta uma sociedade glocalizada, evidenciando que global e local podem coexistir dinamicamente.

Declaro que, não obstante a força da literatura acadêmica, respaldando essa tendência culturológica, só me convenci da sua validade e irreversibilidade ao resgatar minhas raízes sertanejas depois de 50 anos de distância física, sem nunca ter negligenciado o cultivo de minhas fontes espirituais.

Sou um intelectual confessadamente interiorano, homem de província e cidadão fiel 
à cultura sertaneja. Mesmo percorrendo os caminhos do mundo e trilhando as rotas do nosso continente, preservei o meu orgulho caeté, naquela acepção antropológica tão bem dimensionada por Graciliano Ramos. Tanto em seu romance de estreia quanto posteriormente, explicitando-a nas vidas secas que traduzem a identidade renitente de seus personagens emblemáticos.

Durante todos esses anos de exílio contingencial na "terra da garoa", mantive frequentes contatos com meu povo, sem notar dissonâncias radicais no território que mestre Graça outrora carimbou como "terra dos mandacarus". Mas eis que minha comunidade se revelou paradigmática daquilo que, há pouco, chamei de sociedade glocal. Pois bem, a cidade onde vivi toda a minha infância e adolescência saltava da condição de terreno estéril para a gestação da imprensa, convertendo-se em território propício ao nascimento da internet.

Se os jornais ali não passaram das primeiras edições, hoje a mídia digital mostra-se fértil, abrigando 3 portais, que fortalecem as remanescentes identidades comunitárias, reatando os laços desfeitos com a partida de tantos migrantes, hoje povoando a diáspora nordestina espalhada pelo Brasil afora.

Santana do Ipanema aproxima-se, hoje, no Estado de Alagoas, ao estágio em que vislumbrei 
Campina Grande, na região Nordeste, há meio século atrás. Ainda estão vivas, na minha memória, as imagens que guardo desta cidade cosmopolita, quando a visitei pela primeira vez, em 1961. Comparada com a pobreza comunicacional do meu pedaço sertanejo, sem jornais, rádios e outros meios de difusão cultural, Campina Grande incorporou-se ao meu imaginário como paradigma da grandeza midiática, ou seja, como ideal a ser atingido pelas demais comunidades nordestinas.

Além de possuir jornal diário, sustentado pela pujança do comércio agropecuário, Campina Grande ostentava já os sinais de polo universitário regional. Tanto assim que sediava um encontro nordestino dos estudantes de direito, promovido pela UNE e já então apoiado por instituições de prestígio nacional, como a SUDENE. Participar desse congresso estudantil foi a motivação que me trouxe a esta progressista cidade, no início da minha caminhada intelectual.

Matuto alagoano, recém chegado à capital nordestina, impressionou-me o orgulho dos pernambucanos que falavam "diretamente para o mundo", não só através das ondas hertzianas, inauguradas pioneiramente em 1919 (antes mesmo da capital federal), mas que desbravaram o universo televisivo, inaugurando 
simultaneamente as duas primeiras emissoras nordestinas de televisão.

Sem esquecer que Recife já sediava o "mais antigo jornal diário em circulação na América Latina", fiquei extasiado ao reconhecer em Campina Grande a potencialidade de uma metrópole em crescimento, a maior do interior em toda a região.

Comparei, assim, as três referências urbanas que faziam parte do meu repertório cognitivo - a estagnação cultural de Santana do Ipanema, o poderio político historicamente acumulado por Recife e a força econômica do desenvolvimentismo sustentado que exibia 40 Campina Grande - e não tive dúvida em eleger o terceiro modelo como ideal de progresso a ser atingido pela cidade onde me iniciara no jornalismo e da qual me apartava pela carência de oportunidades educacionais.

Reconheço que ao visitar, em anos recentes, minha terra adotiva, voltei a recordar a minha primeira visita a Campina Grande. Esta lembrança permaneceu no meu relicário mítico como patamar ambicionado para libertar Santana do Ipanema daquele estágio angustiante de alienação estagnadora, tão bem descrito pelo nosso contista maior, Breno Accioly. Faço aqui um parêntese para explicar que nasci em Palmeira dos Índios, cidade vizinha, cená- 
rio das narrativas que consagraram o mestre Graciliano Ramos na literatura brasileira.

Por que tirei do baú de recordações as pretéritas imagens míticas de Campina Grande? Justamente porque ali identifiquei sinais de rompimento das amarras que podem livrar Santana do Ipanema da "maldição do cigano". Rememoro o símbolo cultivado pelo imaginário coletivo, incorporado literariamente ao nosso acervo comunitário pelo memorialismo de Oscar Silva, outro intelectual nativo que engrossou o universo da diáspora santanense espalhada pelo território nacional.

Além de intercomunicar-se "diretamente com o planeta", através da internet, passo maior do que o esboçado pelos pernambucanos em tempos de guerra, podem os sertanejos alagoanos, em tempos de paz, participar do universalismo cognitivo que já era privilégio dos paraibanos da serra da Borborema, há muitas décadas passadas. Se há poucos anos, sediávamos a unidade zotécnica da universidade estadual, a partir de agora passamos a dispor, também, do polo de negócios da universidade federal.

Para celebrar o ingresso de minha comunidade na sociedade do conhecimento, etapa vencida por Campina Grande décadas atrás, organizei um livro coletivo, reunindo ensaios produzidos pela nossa diáspora intelectual, 
sob o título Sertão Glocal, complementado por um subtítulo eivado de significação telúrica - "Um mar de novas ideias brota às margens do Ipanema".

Desculpem os colegas se os estou distraindo com fatos referentes a situações exógenas ao contexto da cerimônia que hoje nos reúne. Mas se o faço é pelo desejo de exortar a vanguarda dos intelectuais desta universidade a produzir obra semelhante à que a EDUFAL vai lançar dentro de poucos dias.

E aí está o ônus de tal galardão. Já que vocês me condecoram, desejo exercer de fato o poder embutido nessa homenagem. Quero desafiar

42 os colegas do Departamento de Comunicação da UEPB a escreverem livro semelhante ao que acabo de mencionar.

Trata-se de tarefa inadiável, com a qual estão comprometidos e dela não podem fugir, nem continuar adiando. Proponho que socializem as experiências aqui desenvolvidas no sentido de vislumbrar uma "outra comunicação". Trata-se de ousadia que thes confere singularidade no panorama nacional, mas que permanece desconhecida da nossa comunidade acadêmica. Somente uns poucos que conhecem historicamente o trabalho aqui promovido, de modo contínuo e consciente, podem testemunhar a valorização que merecem o popular, o regio- 
nal e o tradicional no conjunto das expressões comunicacionais pesquisadas e/ou ensinadas.

Dessa maneira, quero encorajá-los a continuar pensando alternativamente e agindo solidariamente. Vocês representam um diferencial qualitativo no panorama nacional dos estudos de comunicação, mas se escondem modestamente nos limites impostos pelas muralhas do "gueto acadêmico". Por isso mesmo, ao me honrarem com título tão generoso, sinto-me no dever de alertá-los civicamente e de convocá-los politicamente para sair das muralhas onde o elitismo acadêmico nos condenou a viver de maneira cômoda, tranquila e apática.

Vamos superar esse imobilismo, compartilhando com as forças vivas da sociedade o conhecimento que produzimos à custa dos impostos pagos pelos cidadãos. Pelo menos três caminhos estão abertos: o da comunicação regional, o da divulgação científica e da cultura dos marginalizados. A iniciativa de sediar este congresso de ciências da comunicação na região Nordeste é um primeiro passo corajoso.

Aqui e agora vocês podem explicar aos colegas dos estados vizinhos o que fazem, pesquisam e aplicam, sem temor de confessar sua vocação acadêmica e de democratizar o conhecimento produzido. Na sequência, pre- 
cisam sair da província, exaltando seus valores identitários.

Três perguntas demandam explicação nacional. Só vocês podem esclarecer e justificar:

1. Por que Campina Grande se converteu em polo emblemático de mídia regional, historicamente consolidado e periodicamente reciclado? Esse modelo pode ser replicado em outras regiões? Como? Onde? Cabe aos pesquisadores de comunicação regional elucidar a questão.

2. Campina Grande despontou no cenário acadêmico brasileiro como núcleo científico de ponta, onde o Estado fez investimentos para criar tecnologia de última geração destinada a respaldar o desenvolvimento nacional. Qual o impacto dessas inovações científicas no sistema produtivo? Eis uma tarefa a mobilizar a atenção dos estudiosos da divulgação científica.

3. Como transformar um slogan publicitário em conhecimento sistemático? Se Campina Grande tem o maior forró do mundo, em que consiste o fenômeno e como ele se renova continuamente, atraindo multidões nas festas juninas da colheita agrícola e alimentando uma rede bem nutrida de serviços culturais? 
Aqui está a esfinge a ser decifrada pelos analistas da folkcomunicação. A comunidade nacional e a vanguarda internacional das ciências da comunicação querem saber mais: o quê, quando e onde, mas também deseja entender o como e está curiosa pela compreensão dos porquês.

Aqui fica a lição de casa para os que me causaram tamanha alegria ao ser incluído no quadro de honra desta universidade.

Numa conjuntura marcada pelo ceticismo, niilismo e derrotismo, vai fazer bem ao povo da comunicação tomar conhecimento das aspirações comunicacionais do povo real, aquele que padece horas a fio na servidão muscular, amassando com as próprias mãos o barro da vida cotidiana. E também buscando lenitivos nos processos de interlocução simbólica que the dão alento, esperança e segurança para continuar lutando e sobrevivendo, até a conquista de uma sociedade justa e mais humana. 